\title{
TERMOGRAVIMETRIA: UM NOVO ENFOQUE PARA A CLÁSSICA DETERMINAÇÃO DE CÁLCIO EM CASCAS DE OVOS ${ }^{\#}$
}

\author{
Júnia G. Pereira, Fabiano Okumura, Luiz A. Ramos e Éder T. G. Cavalheiro* \\ Instituto de Química de São Carlos, Universidade de São Paulo, CP 780, 13560-970 São Carlos - SP, Brasil \\ Joaquim A. Nóbrega \\ Departamento de Química, Universidade Federal de São Carlos, CP 676, 13560-970 São Carlos - SP, Brasil
}

Recebido em 15/3/08; aceito em 5/2/09; publicado na web em 28/7/09

\begin{abstract}
TERMOGRAVIMETRY: A NEW APPROACH FOR THE CLASSIC DETERMINATION OF CALCIUM IN EGGSHELLS. The use of thermoanalytical data in sample preparation is described as a tool to catch the students' attention to some details that can simplify both the analysis and the analytical procedure. In this case, the thermal decomposition of eggshells was first investigated by thermogravimetry (TGA). Although the classical procedures suggest long exposure to high temperatures, the TGA data showed that the decomposition of organic matter takes place immediately when the sample is heated up to $800{ }^{\circ} \mathrm{C}$ under air atmosphere. After decomposition, the calcium content was determined by flame atomic emission photometry and compared with the results obtained using classical volumetric titration with EDTA.
\end{abstract}

Keywords: thermogravimetry; flame atomic emission photometry; sample preparation.

\section{INTRODUÇÃO}

A determinação de cálcio em cascas de ovos é um experimento clássico, frequentemente empregado no ensino de química analítica quantitativa e de análise instrumental. Há vários experimentos simples usando o carbonato de cálcio contido nessas cascas, para demonstrar princípios de ácidos e bases, entre outros. ${ }^{1,2}$

A principal função do carbonato na casca é conferir dureza e resistência mecânica, ${ }^{3,4}$ podendo ser um parâmetro para definir condições da saúde do animal e um guia para controle de sua nutrição.

Além disso, as cascas têm sido usadas como fonte de cálcio na alimentação de pessoas carentes. ${ }^{5,6}$ Portanto, a determinação do teor de cálcio em cascas de ovos, não apresenta apenas aspectos didáticos e acadêmicos, sendo importante também na produção animal e até na nutrição humana.

A análise térmica compreende um conjunto de técnicas que medem a variação em uma propriedade física de uma amostra submetida a uma programação controlada de temperatura, como foi definido por MacKenzie ${ }^{1,7}$ e previamente discutido nesse periódico. ${ }^{8,9}$ Dentre as técnicas de análise térmica mais usadas está a termogravimetria (TG), a qual acompanha a variação da propriedade física massa, enquanto a amostra é aquecida.

A perda de massa pode ser relacionada com muitos fenômenos, como desidratação, sublimação, decomposição, entre outros, que podem servir para diferentes aplicações, resumidas por Ionashiro, ${ }^{10}$ como: estudo de decomposição térmica de minerais, minérios, carvão, petróleo, madeira, polímeros, alimentos, materiais explosivos etc; estudos sobre corrosão de metais em atmosfera controlada, em faixas amplas de temperatura; estudos sobre a velocidade de evaporação de líquidos e sublimação de sólidos.

Apesar da grande aplicabilidade, as técnicas de análise térmica nem sempre são apresentadas aos estudantes de graduação, pois dado

\# Este trabalho é dedicado ao Prof. Dr. Massao Ionashiro (Prof. Emérito do IQ-UNESP), pela sua atuação incansável no ensino e na difusão do uso das técnicas termoanalíticas.

*e-mail: cavalheiro@iqsc.usp.br o custo dos equipamentos, estes, geralmente, não estão disponíveis em laboratórios didáticos.

Por outro lado, a fotometria de chama é a mais simples das técnicas analíticas baseadas em espectroscopia atômica. Nesse caso, a amostra contendo cátions metálicos é inserida por nebulização em uma chama e analisada pela quantidade de radiação emitida pelas espécies atômicas ou iônicas excitadas. Os íons em solução são levados à fase gasosa na forma elementar e, ao receberem energia de uma chama, geram espécies excitadas que retornam para o estado fundamental liberando parte da energia recebida na forma de radiação, em comprimentos de onda característicos para cada elemento químico. ${ }^{1,11-13}$

A simplicidade inerente da técnica já foi objeto de uma proposta para desenvolver experimentos simples e de relativo baixo custo para cursos de análise instrumental. ${ }^{11}$ Naquela oportunidade foram propostos vários experimentos para determinação de íons de metais alcalinos e alcalino-terrosos em amostras do cotidiano, tais como: águas naturais, bebidas isotônicas, pilhas, soro fisiológico e um medicamento contendo lítio. Um histórico contextualizando o desenvolvimento da técnica e da teoria atômica também foi apresentado, assim como seus fundamentos teóricos.

Neste trabalho, um projeto simples para graduação é apresentado visando demonstrar princípios de preparo de amostra e sua aplicação na determinação do teor de cálcio em um exemplo do cotidiano, representado pelas cascas de ovos, com base em resultados termogravimétricos.

O tempo de queima das amostras em mufla pode ser drasticamente reduzido, de acordo com o perfil da curva TG, com a exposição das cascas ao oxigênio do ar.

\section{PARTE EXPERIMENTAL}

\section{Equipamentos}

Nos experimentos realizados foram utilizados um fotômetro de chama DM-61 (Digimed) com câmara de nebulização para introdução de combustível e ar comprimido. As condições de operação recomendadas pelo fabricante foram utilizadas neste trabalho e envolvem: taxa 
de aspiração de $5 \mathrm{~mL} \mathrm{~min}{ }^{-1}$, combustível gás liquefeito de petróleo (GLP), oxidante: ar, isento de pó e óleo, pressão de 20 psi, vazão 9 $\mathrm{mL} \mathrm{min}^{-1}$, filtro de interferência com banda passante de $589 \pm 12 \mathrm{~nm}$, para sódio, fornecido pelo fabricante.

Um micro moinho tipo Willye (Marconi, MA-048) foi usado no preparo das amostras. Um módulo termogravimétrico simultâneo TG/DTA Q600, (TA Instruments), operando nas condições descritas a seguir. Os espectros vibracionais na região do infravermelho (IV) foram obtidos em um espectrofotômetro Nicolet 5SXC. As diluições para preparo das curvas analíticas foram efetuadas com micropipetadores Eppendorf com diferentes volumes.

\section{Reagentes e soluções}

Em todos os experimentos foram utilizadas soluções estoque em concentração $1000,0 \mathrm{mg} \mathrm{L}^{-1}$ preparadas a partir de carbonato de cálcio (Mallinckrodt). As soluções foram preparadas com água desionizada, imediatamente após secagem dos sais por 24 h, à 110 ${ }^{\circ} \mathrm{C} .{ }^{13} \mathrm{O}$ carbonato de cálcio foi dissolvido com $\mathrm{HCl}$ concentrado e a solução resultante foi diluída para $1 \mathrm{~L}$ com água desionizada. Também foi preparada uma solução de cloreto de lantânio (Aldrich) $10 \% \mathrm{~m} \mathrm{v}^{-1}$, em ácido nítrico. A solução foi usada para as determinações de cálcio, considerando-se a presença de fosfato na amostra.

A partir da solução estoque de cálcio prepararam-se, por diluição, soluções de referência contendo 2,00; 5,00; 10,0; 20,0; 30,$0 ; 40,0 ; 50,0 ; 60,0$; e $80,0 \mathrm{mg} \mathrm{L}^{-1}$. Adicionou-se uma alíquota da solução de óxido de lantânio $10 \%\left(\mathrm{~m} \mathrm{v}^{-1}\right)$ a cada uma dessas soluções, de forma a obter uma concentração de $\mathrm{La}^{3+}$ igual a $1 \%$ $\left(\mathrm{m} \mathrm{v}^{-1}\right)$. Os íons $\mathrm{La}^{3+}$ reagem com os íons fosfato e silicato, que podem eventualmente estar presentes nas amostras, evitando a supressão do sinal de cálcio. ${ }^{1}$

\section{Obtenção e tratamento das cascas de ovos}

As amostras utilizadas nestes experimentos foram cascas de ovos de galinha e codorna. As mesmas foram previamente submetidas aos seguintes procedimentos de limpeza: cascas de ovos de codorna foram obtidas após cozimento dos ovos em água fervente por $15 \mathrm{~min}$. Após resfriamento, as cascas foram retiradas, lavadas com detergente e, em seguida, enxaguadas em água corrente e posteriormente com água destilada, acondicionadas em placas de Petri e secas em estufa a $40{ }^{\circ} \mathrm{C}$ por $6 \mathrm{~h}$. Alternativamente, a secagem pode ser feita ao sol por aproximadamente $8 \mathrm{~h}$, tomando-se o cuidado de cobrir o recipiente com filme de PVC (papel filme) perfurado com uma agulha de injeção, para evitar contaminação por poeira. $^{1}$

Já as cascas de ovos de galinha foram gentilmente cedidas pelo refeitório do Campus da USP de São Carlos. Nesse caso, as cascas foram obtidas de ovos crus, lavadas com detergente e enxaguadas com água corrente. Finalmente, foram enxaguadas com água destilada, acondicionadas em placas de Petri e secas em estufa a $40{ }^{\circ} \mathrm{C}$ por 6 h. Alternativamente, a secagem pode ser feita ao sol por aproximadamente $8 \mathrm{~h}$, tomando-se o cuidado de cobrir o recipiente com filme de PVC (papel filme) perfurado com uma agulha de injeção, para evitar contaminação por poeira. ${ }^{1}$

Após secagem, as cascas foram trituradas no moinho tipo Willye, com a peneira de 30 mesh, resultando em um pó fino, que foi acondicionado em um frasco de polipropileno previamente lavado. $\mathrm{O}$ frasco foi mantido em dessecador sobre sílica gel. ${ }^{1}$

\section{Determinação de cálcio por fotometria e EDTA}

As amostras foram calcinadas em mufla até $800{ }^{\circ} \mathrm{C}$, ao ar, em cadinhos de porcelana. Camadas finas de amostra propiciaram a obtenção do óxido de cálcio que, após resfriamento em dessecador, foi retomado em $\mathrm{HCl}$ diluído e submetido à medida no fotômetro de chama e por EDTA.

No caso do fotômetro foram traçadas curvas analíticas entre 2,00 e 80,0 mg L-1, medindo-se cada padrão em quintuplicata. As amostras de cálcio obtidas a partir do material calcinado em mufla foram medidas em quintuplicata.

As mesmas amostras foram também tituladas com EDTA 0,010 mol L ${ }^{-1}$, usando negro de eriocromo-T (NET) como indicador, em $\mathrm{pH}$ 10,0 controlado com tampão amônia/cloreto de amônio. ${ }^{14}$

\section{Obtenção das curvas termogravimétricas}

As medidas termogravimétricas foram obtidas em um módulo termogravimétrico simultâneo TG/DTA Q600 (TA-Instruments) usando massa de amostra em torno de $7 \mathrm{mg}$ em cadinhos de alumina e razão de aquecimento de $10{ }^{\circ} \mathrm{C} \mathrm{min}^{-1}$. A atmosfera do forno foi saturada com ar seco a uma vazão constante de $100 \mathrm{~mL} \mathrm{~min}^{-1}$.

Como nem sempre há disponibilidade desse equipamento nos laboratórios didáticos, a curva pode, alternativamente, ser obtida em um laboratório de pesquisa e feita uma demonstração do uso do equipamento para os alunos em grupos.

\section{Obtenção dos espectros de IV}

Os espectros IV foram obtidos após calcinar as amostras em mufla a $800{ }^{\circ} \mathrm{C}$ por 15 min ao ar e previamente à medida de cálcio no fotômetro e por EDTA. Os cadinhos foram retirados da mufla, ainda a $100{ }^{\circ} \mathrm{C}$ e pequenas porções foram usadas na preparação de pastilhas de $\mathrm{KBr}$, contendo aproximadamente $1 \%$ do material calcinado.

\section{RESULTADOS E DISCUSSÃO}

Os resultados descritos a seguir foram obtidos pelos autores deste trabalho. Visando uma aplicação didática, os alunos preparariam as soluções (estoque e padrões) e respectivas amostras. Usando a termogravimetria fariam os estudos da decomposição das amostras e analisariam os resultados. Finalmente, fariam a calcinação em mufla, dissolveriam os resíduos com $\mathrm{HCl}$ e realizariam as leituras em fotômetro de chama e tratariam os dados obtidos, com a opção de compará-los com a técnica clássica de titulação com EDTA. O projeto todo consumiria 3 aulas de $4 \mathrm{~h}$ de atividade em laboratório.

\section{Curvas TG para as cascas de ovos}

Normalmente, os procedimentos didáticos sugerem a decomposição da casca de ovo pela queima da matéria orgânica em mufla por longas horas a $800{ }^{\circ} \mathrm{C}$ ao ar. Entretanto, ao analisar as cascas de ovos de codorna e galinha na termobalança, sob atmosfera de ar, os resultados indicaram que a decomposição ocorre rapidamente, o que possibilitaria uma redução drástica no tempo de análise, conforme se observa nas curvas da Figura 1.

As curvas TG para ambas as amostras (Figura 1) sugerem uma decomposição de ambas as amostras em três etapas, porém, com diferenças nas perdas de massa.

No caso das cascas de ovos de galinha, em uma primeira etapa, ocorre a remoção de água com perda de massa em torno de 1,03\% entre 25 e $226^{\circ} \mathrm{C}$. A seguir, observa-se a decomposição da matéria orgânica, com perda de 3,77 \% em um intervalo de temperatura de $226-574{ }^{\circ} \mathrm{C}$. Em uma terceira etapa ocorre à perda de massa de $42,17 \%$ entre 574 e $769^{\circ} \mathrm{C}$, que estaria relacionada à liberação de 

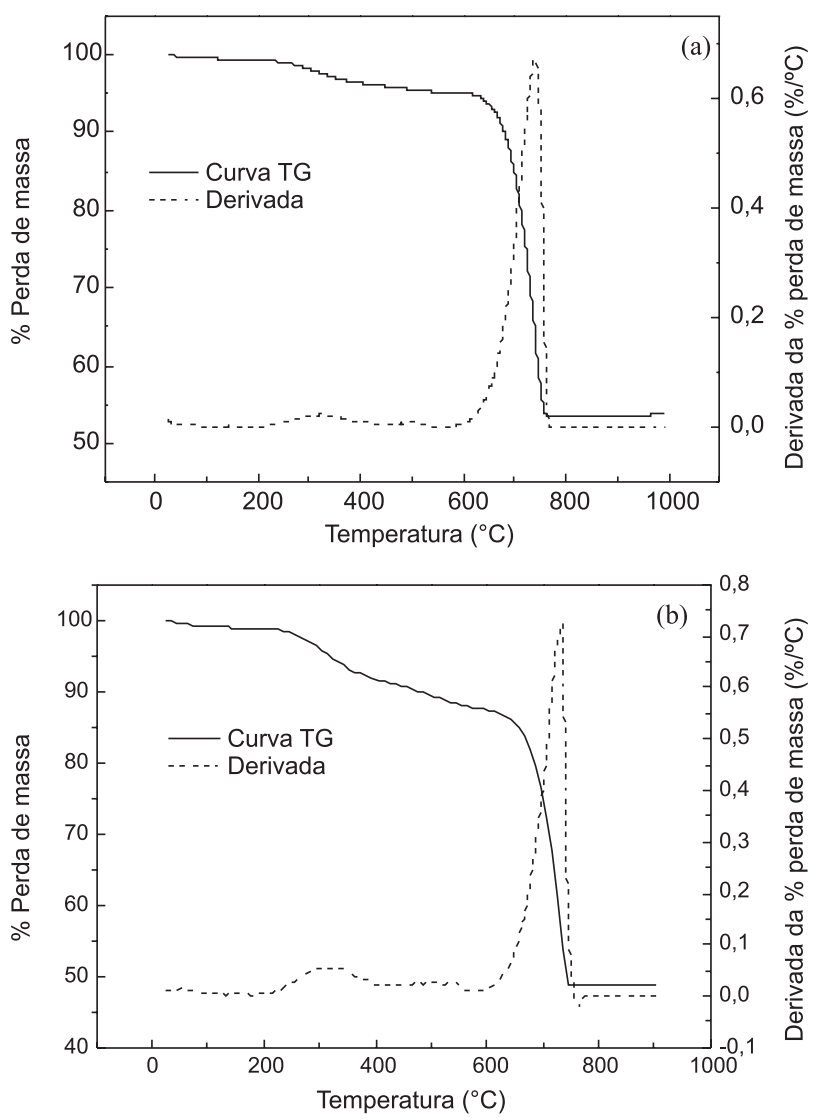

Figura 1. Curvas TG (linha cheia) e DTG (linha pontilhada) das cascas de ovos de (a) galinha e (b) codorna

$\mathrm{CO}_{2}$ proveniente da decomposição do $\mathrm{CaCO}_{3}{ }^{7} \mathrm{~A} 800{ }^{\circ} \mathrm{C}$, a amostra apresentou um resíduo de $53,03 \%$ no suporte da amostra, referente às cinzas e compostos inorgânicos. Este resíduo foi caracterizado por IV, tendo-se concluído tratar-se predominantemente de óxido de cálcio resultante da decomposição de $\mathrm{CaCO}_{3}{ }^{2,7}$

A quantidade de $\mathrm{CaCO}_{3}$ pode ser determinada pela perda de $\mathrm{CO}_{2}$ no terceiro evento térmico, através da Equação 1:

${ }_{0} \mathrm{CaCO}_{3}=\Delta_{m} \times \frac{\mathrm{MM}_{\mathrm{CaCO}_{3}}}{M_{\mathrm{CO}_{2}}}=42,17 \% \times \frac{100,09 \mathrm{gmol}^{-1}}{44,01 \mathrm{gmol}^{-1}}=95,90 \%$

sendo $\Delta_{\mathrm{m}}$ a perda de massa (\%), medida no evento.

Segundo informações da literatura, a casca de ovo de galinha é composta de $93 \%$ de carbonato de cálcio, $5 \%$ de matéria orgânica, $1,5 \%$ de água $(\mathrm{m} / \mathrm{m})$ e traços, de carbonato de magnésio, fosfato de cálcio e fosfato de magnésio. ${ }^{4}$ Obviamente essa composição varia dependendo, por exemplo, da alimentação, da idade da ave etc.. Dessa forma, pode-se concluir que a análise por TG é concordante com a composição proposta na literatura.

No caso dos ovos de codorna, observou-se uma perda de massa da ordem de 1,49\%, atribuída à desidratação da amostra, entre 25 e $203{ }^{\circ} \mathrm{C}$. Em seguida, ocorreu a decomposição da matéria orgânica, com perda de $10,80 \%$ da massa inicial entre 203 e $580{ }^{\circ} \mathrm{C}$, e a decomposição do carbonato de cálcio entre 580 e $764{ }^{\circ} \mathrm{C}$, com perda de $38,75 \%$. A $800{ }^{\circ} \mathrm{C}$ obteve-se um resíduo de $48,94 \%$ no suporte de amostra, atribuído à presença de cinzas e materiais inorgânicos, preferencialmente $\mathrm{CaO}$, segundo caracterização por IV.

Um cálculo semelhante ao realizado para a mostra de ovo de galinha, usando a Equação 1 revela um teor de $\mathrm{CaCO}_{3}$ da ordem de $88,13 \%$, para esta amostra. Não foi encontrada na literatura uma descrição da composição das cascas de ovos de codorna para comparação, mas elas apresentaram maior teor de matéria orgânica, segundo as curvas TG.

\section{Caracterização dos resíduos de queima das cascas de ovos}

A termogravimetria é uma técnica essencialmente quantitativa. Desta forma recomenda-se que os intermediários de cada etapa do processo de decomposição térmica, assim como os resíduos finais de degradação sejam caracterizados usando-se técnicas complementares. ${ }^{7}$ Entretanto, nem sempre se obtêm quantidades suficientes de resíduos para realizar tais análises diretamente da termobalança. Quando isso ocorre, é comum realizar experimentos preparativos, nos quais maiores quantidades de amostras são submetidas a aquecimento em mufla, usando-se condições de aquecimento o mais próximo possível das usadas na termobalança.

Neste exemplo, os resíduos obtidos na decomposição das cascas de ovos de galinha e codorna foram analisados por espectroscopia no infravermelho (IV), Figura 2, usando-se amostras preparadas em mufla, segundo as condições obtidas das curvas TG. Na mesma figura é apresentado o espectro IV do $\mathrm{CaO}$ - PA, usado como referência para comparação.
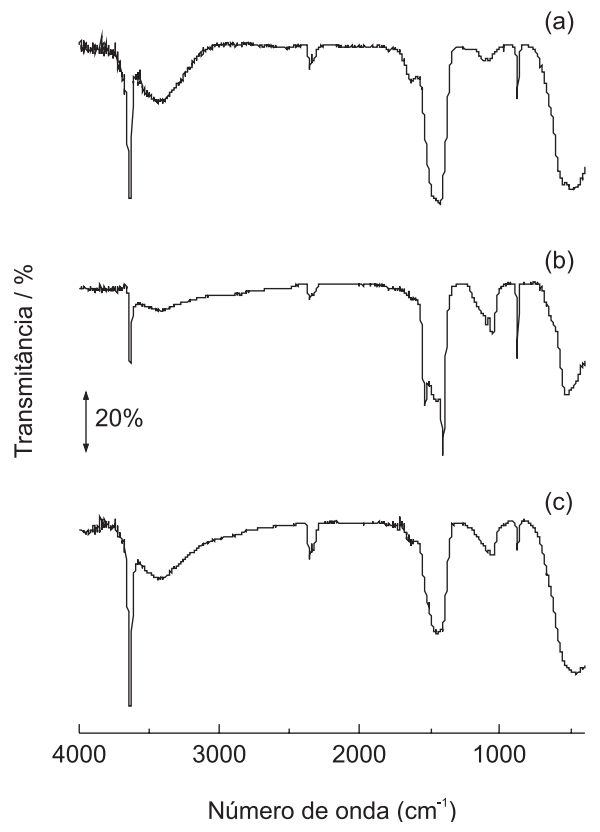

Figura 2. Espectros de infravermelho de (a) CaO - PA, (b) resíduo da queima da amostra de casca de ovo de cordona, (c) resíduo da queima da amostra de casca de ovo de galinha, obtidos em mufla nas mesmas condições da TG. Todos os espectros foram obtidos a temperatura ambiente, em pastilhas de $\mathrm{KBr}$

É bem conhecido que a decomposição dos carbonatos de metais alcalinos ocorre por meio da perda de $\mathrm{CO}_{2}$ e geração dos respectivos óxidos, em temperaturas características que aumentam com a massa molar do metal..$^{7,15} \mathrm{O}$ carbonato de cálcio se decompõe tipicamente entre $650-800{ }^{\circ} \mathrm{C}$, com ligeiras variações dependendo das condições experimentais, ${ }^{7,15}$ liberando $\mathrm{CO}_{2}$ e gerando $\mathrm{CaO}$ como resíduo. Exemplo clássico é o uso do oxalato de cálcio $(\mathrm{CaOx})$ para calibração das termobalanças: após desidratação, o $\mathrm{CaOx}$ libera $\mathrm{CO}$ produzindo carbonato de cálcio que, na sequência, perde $\mathrm{CO}_{2}$ gerando $\mathrm{CaO}$ como resíduo. ${ }^{7,10}$

A semelhança entre os espectros dos resíduos das cascas dos ovos de galinha e codorna com o do óxido de cálcio PA e os descritos na 
literatura ${ }^{16,17}$ confirma sua presença no resíduo, em ambos os casos. Espectros IV dos resíduos e do $\mathrm{CaO}$ também poderiam ser obtidos pelos alunos. Em adição, quando $\mathrm{HCl}$ 1:1 (v/v) foi gotejado sobre o resíduo suspenso em água, tanto da termobalança, quanto da mufla, não foi observada a efervescência característica da presença de carbonatos, o que prova que o resíduo é óxido de cálcio.

Com relação à atribuição dos picos IV do $\mathrm{CaO}$, trata-se de tema ainda em discussão na literatura, pois o óxido tende a absorver instantaneamente umidade e $\mathrm{CO}_{2}$ do ar, apresentando picos de grupos hidroxila e carbonila, conforme discutido a seguir.

$\mathrm{Na}$ temperatura ambiente, devido à adsorção de umidade e $\mathrm{CO}_{2}$, Kalinkin et al. ${ }^{16}$ observaram que tanto o $\mathrm{CaO}$, quanto o $\mathrm{Ca}(\mathrm{OH})$, reagem com o ar úmido formando $\mathrm{CaCO}_{3}$ amorfo na superfície das partículas. Como consequência, os espectros IV do $\mathrm{CaO}$ e do $\mathrm{Ca}(\mathrm{OH})_{2}$ variam consideravelmente, dependendo das condições em que são tratados mecanicamente, na presença de $\mathrm{CO}_{2}$ e umidade.

Estes autores afirmaram que, sob tais condições, as bandas em 3623 e $3403 \mathrm{~cm}^{-1}$ seriam atribuídas ao estiramento de -OH em $\mathrm{Ca}(\mathrm{OH})_{2}$ e $\mathrm{H}_{2} \mathrm{O}$, respectivamente. A presença destas substâncias foi relacionada com a umidade do ar. Já a banda em $1455 \mathrm{~cm}^{-1}$ foi atribuída ao estiramento de $-\mathrm{CO}_{3}^{2-}$ e se deve à quimiossorção de $\mathrm{CO}_{2}$ na superfície contendo $\mathrm{Ca}(\mathrm{OH})$. Em 1085, pode-se observar a banda de estiramento simétrico de $\mathrm{CO}_{2}$.

Dubletos em 1550/1408 $\mathrm{cm}^{-1}$, bem definidos no espectro do resíduo da casca do ovo de codorna, poderiam ser atribuídos ao $\mathrm{CO}_{2}$ adsorvido em espécies inorgânicas de silicatos, segundo Kalinkin et al. ${ }^{16}$

De acordo com Fukuda e Tanabe, ${ }^{17}$ as bandas em 1060 e $860 \mathrm{~cm}^{-1}$, respectivamente são devidas à presença de $\mathrm{CO}_{2}$ adsorvido na superfície do óxido, quando não há tratamento mecânico.

Blom e Hedderich ${ }^{18}$ observaram que o $\mathrm{CaO}$ produzido por oxidação do metal na fase vapor apresentou oito transições da banda fundamental do óxido de cálcio com radiação de laser. O centro da banda foi proposto em $722,376 \mathrm{~cm}^{-1}$. Isso, porém, só pode ser observado na fase vapor em temperaturas elevadas.

Apesar de que a simples comparação dos espectros pode levar à conclusão de que todos se referem aos mesmos compostos, complementando a informação obtida das curvas TG, a interpretação destes espectros poderia representar uma discussão rica sobre o tema.

\section{Considerações sobre o tempo de tratamento das amostras}

Os resultados das curvas TG (Figura 1) e a semelhança observada nos espectros da Figura 2 sugerem que as cascas de ovos trituradas se convertem a $\mathrm{CaO}$ após aquecimento ao ar até $800{ }^{\circ} \mathrm{C}$.

De acordo com os perfis das curvas TG, pode-se concluir que a decomposição ocorre assim que a temperatura de cada evento térmico é atingida. A decomposição do $\mathrm{CaCO}_{3}$ a $\mathrm{CaO}$ se dá em intervalos de temperatura de $570-760{ }^{\circ} \mathrm{C}$. Desta forma, era de se esperar que a decomposição das cascas de ovos pudesse ser realizada em mufla durante o processo de aquecimento das amostras, bastando um curto período a $800{ }^{\circ} \mathrm{C}$ para a mineralização completa.

Um experimento foi realizado, aquecendo-se uma camada espessa de cascas de ovos de galinha, em um cadinho de porcelana, como geralmente é feito em aulas de química experimental, visando a determinação de cálcio em cascas de ovos. $\mathrm{O}$ aquecimento foi realizado em mufla da temperatura ambiente até $800{ }^{\circ} \mathrm{C}$, a $10{ }^{\circ} \mathrm{C} \mathrm{min}{ }^{-1}$ e mantendo-se a amostra aquecida a $800{ }^{\circ} \mathrm{C}$ durante $1 \mathrm{~h}$, sempre sob ar. $\mathrm{O}$ mesmo lote de cascas usadas na termogravimetria foi usado aqui, procurando-se manter as mesmas condições experimentais, para comparação.

Ao remover o cadinho da mufla, observa-se a conversão da ca-
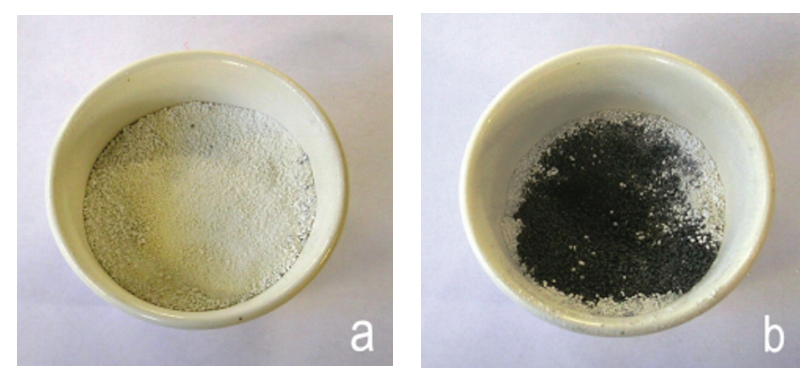

Figura 3. Amostras de casca de ovo de galinha durante a calcinação de uma massa espessa após $1 \mathrm{~h}$ de aquecimento a $800^{\circ} \mathrm{C}$, ao ar: (a) vista da camada superior, já oxidada na cor branca e (b) vista da mesma amostra, após remoção da camada superior, mostrando a porção carbonizada, não exposta ao oxigênio

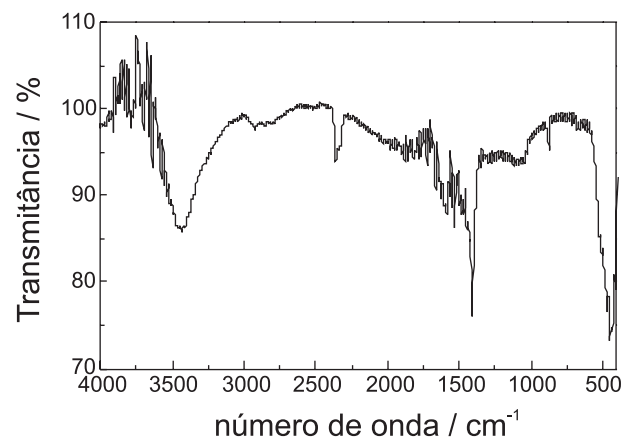

Figura 4. Espectro de IV da camada superior da amostra de ovo de galinha queimada a $800{ }^{\circ} \mathrm{C}$ durante $1 \mathrm{~h}$, obtido imediatamente após sair da mufla

mada superior da amostra, que perde o tom ligeiramente amarelado da casca tornando-se branca (Figura 3a) e o espectro IV da camada superior, obtido imediatamente após retirá-la da mufla (Figura 4), mostra que se trata de $\mathrm{CaO}$.

Entretanto, ao se remover esta camada superior já convertida a $\mathrm{CaO}$, nota-se uma carbonização da parte inferior, a qual ainda não foi exposta ao ar (Figura 3b).

Assim, pode-se propor que o tempo de calcinação pode ser drasticamente diminuído se a amostra for disposta em camadas finas e queimada a $800{ }^{\circ} \mathrm{C}$, permitindo o acesso do ar a todo o conteúdo, ao mesmo tempo. Isto acontece na termobalança, onde se usam 10 mg de amostra.

Por outro lado, quando se usam camadas mais espessas de cascas moídas a oxidação se dá de forma lenta, requerendo várias horas de aquecimento, para permitir a degradação completa da parte orgânica, a $\mathrm{CO}_{2}$ e $\mathrm{H}_{2} \mathrm{O}$, restando a fração mineral, composta principalmente por $\mathrm{CaO}$.

Eventualmente, a exposição por $16 \mathrm{~h}$ pode levar à decomposição de outros constituintes minerais minoritariamente presentes na casca, mas as curvas TG dão um forte indicativo de que, nestas condições, a amostra é convertida preferencialmente a $\mathrm{CaO}$, como demonstram os espectros de IV.

\section{Determinação de cálcio nas cascas de ovos}

Com base nestes resultados, concluiu-se que as amostras podem ser decompostas por aquecimento em mufla até $800^{\circ} \mathrm{C}$, em uma razão de aquecimento de $10{ }^{\circ} \mathrm{C} \mathrm{min}^{-1}$, mantendo-se uma isoterma durante 15 min e usando camadas finas de cascas moídas. Considerando-se a temperatura ambiente em torno de $25^{\circ} \mathrm{C}$, o tempo total de aqueci- 
Tabela 1. Teores de cálcio em cascas de ovos de galinha e codorna em \% $\left(\mathrm{m} \mathrm{m}^{-1}\right)$, usando espectrometria de emissão atômica e titulação complexométrica

\begin{tabular}{lccccc}
\hline Amostra & Teor de cálcio ${ }^{\mathrm{a}}(\mathrm{g})$ & & & & \\
\hline Erro $(\%)$ & $\mathrm{t}-$ Student $^{*}$ & Fotometria $^{\mathrm{b}}$ & Complexométria $^{\mathrm{c}}$ & Calculado & Tabelado $^{\mathrm{d}}$ \\
Galinha & $0,37 \pm 0,01$ & $0,37 \pm 0,01$ & 1,3 & 0,57 & 4,20 \\
Codorna & $0,36 \pm 0,01$ & $0,37 \pm 0,01$ & 1,7 & 0,99 & 4,20 \\
\hline
\end{tabular}

${ }^{\mathrm{a}}$ Massa de cálcio / massa de casca de ovo. ${ }^{\mathrm{b}}$ Medidas em quintuplicata. ${ }^{\mathrm{c}}$ Medidas em triplicata. ${ }^{\mathrm{d}} \mathrm{Para} 95 \%$ de confiança ${ }^{18}$.

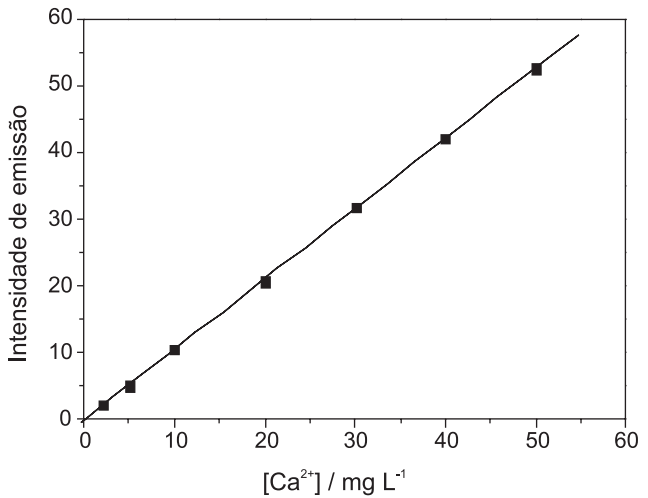

Figura 5. Curva analítica para cálcio, obtida usando o fotômetro de chama. Cada ponto é a média de cinco determinações. Neste intervalo de concentração obteve-se uma relação linear representada pela Equação 3, do texto

mento é de cerca de 90 min:

$t=\frac{(800-25)^{\circ} \mathrm{C}}{10^{\circ} \mathrm{C} \min ^{-1}}+15 \min =90 \min$

A determinação da intensidade de emissão em função da concentração dos padrões forneceu a curva analítica apresentada na Figura 5, cuja reta obedeceu à seguinte equação linear:

$y=0,0058+1,06\left[\mathrm{Ca}^{+2}\right], \mathrm{n}=7$ e $\mathrm{R}=0,9999$

Usando esta curva analítica mediram-se as intensidades de emissão para as amostras e partir destes dados calcularam-se os teores de cálcio nas cascas de ovos de galinha e codorna. Os resultados obtidos encontram-se na Tabela 1.

Para efeito de comparação dos resultados, além das medidas no fotômetro, foram realizadas análises das amostras por titulação complexométrica, usando EDTA como titulante e negro de eriocromo-T como indicador em tampão amônio pH 10. Os resultados obtidos com os dois métodos e os respectivos erros estão apresentados na Tabela 1 .

A comparação das médias obtidas foi realizada usando o test tStudent. Para tanto, foi utilizada a Equação 4, para cálculo do desvio padrão pareado, conforme descrito por Harris: ${ }^{19}$

$s_{p}=\sqrt{\frac{\sum_{\text {media } 1}\left(x_{i}-\bar{x}_{1}\right)^{2}+\sum_{\text {media } 2}\left(x_{j}-\bar{x}_{2}\right)^{2}}{n_{1}+n_{2}-2}}$

na qual s $\mathrm{p}_{\mathrm{p}}$ é o valor de desvio padrão pareado; $\mathrm{x}_{\mathrm{i}}$ e $\mathrm{x}_{\mathrm{j}}$ são os valores medidos; $\bar{x}_{1} \mathrm{e} \bar{x}_{2}$ são os valores médios obtidos e $\mathrm{n}_{1}$ e $\mathrm{n}_{2}$ são os números de medidas efetuados para obter cada conjunto de resultados pelos métodos 1 e 2 , respectivamente.

De posse deste valor calcula-se o valor de t-Student pela Equação 5:

$t=\frac{\bar{x}_{1}-\bar{x}_{2}}{s_{p}} \sqrt{\frac{n_{1} n_{2}}{n_{1}+n_{2}}}$

Quando os valores de t calculado pela Equação 5 são menores que os valores de $\mathrm{t}$ tabelado, as médias podem ser consideradas concordantes, dentro do intervalo de confiança escolhido para o valor do teste de t-Student. ${ }^{18}$

Para esse experimento foi sugerido um intervalo de confiança de $95 \%$. Foram feitas três titulações, o que implica em dois graus de liberdade ( $\mathrm{n}$ e n-1, respectivamente) e 5 medidas no fotômetro (n $=5$ e $n-1=4)$. Os valores de $\mathrm{t}$ calculado e $\mathrm{t}$ tabelado mostram que ao comparar os dois métodos, há concordância de resultados para um intervalo de confiança de $95 \%$ entre a fotometria de chama e a titulação complexométrica.

\section{CONSIDERAÇÕES FINAIS}

O experimento desenvolvido neste trabalho envolve conceitos em espectrometria de emissão atômica e termogravimetria, cujas aplicações podem se estender a diversos tipos de amostra, proporcionando assim flexibilidade para explorar exemplos encontrados no cotidiano dos alunos. Também pode representar uma alternativa interessante para alunos de cursos como Farmácia, Biologia, Alimentos, Nutrição e outras áreas, em função do apelo exercido pelas amostras. Esses experimentos envolvem uma quantidade considerável de conceitos, que abrangem cálculos estequiométricos e estatísticos, entre outros.

Como resultados didáticos, ao final destes experimentos os alunos teriam realizado o seguinte conjunto de atividades:

realização de medidas termogravimétricas e interpretação dos seus resultados em relação a informações da literatura e identificação do resíduo por espectroscopia no IV, usada aqui como técnica complementar; preparação de amostras, cabendo ao professor esclarecer as outras formas de preparo existentes;

realização das medidas com o fotômetro de chama, o que permitiria trabalhar com os conceitos envolvidos nos métodos ópticos de análise, usando um instrumento simples e de custo relativamente baixo;

comparação entre os resultados obtidos com uma técnica instrumental e uma técnica clássica, observando as vantagens e desvantagens de cada uma, com a possibilidade de estabelecer comparações estatísticas entre os resultados.

\section{REFERÊNCIAS}

1. Okumura, F.; Dissertação de Mestrado, Universidade de São Paulo, Brasil, 2004. 
2. Baccan, N.; Andrade J. C.; Godinho, O. E. S.; Barone, J. S.; Química Analítica Quantitativa Elementar, $3^{a}$ ed., Edgard Blücher: São Paulo, 2001.

3. Solomon, S. E.; Egg and Eggshell Quality, Iowa State University Press: Iowa, 1997; Bahr, J. M.; Johnson, P. A. Em Reproduction in domestic animals; Cupps, P. T., ed.; $4^{a}$ ed., Academic Press: San Diego, 1991; http://www.uff.br/fisiovet/Conteudos/reproducao_aves.htm, acessada em Junho 2007.

4. Silva, J. H. V.; Santos, V. J.; Rev. Bras. Zootec. 2000, 29, 1440.

5. Chaves, N.; Nutrição Básica e Aplicada, Guanabara Koogan: Rio de Janeiro, 1981.

6. http://www.pastoraldacrianca.org.br.htmltonuke.php?filnavn=dicas/ segalim/dicas_maio_2000.htm, acessada em Maio 2007.

7. Wendlandt, W. W. Em Thermal Analysis in Chemical Analysis; Ewing, P. J.; Winefordner, J. D., eds.; $3^{\text {rd }}$ ed., John Willey: New York, 1986, vol. 19,

8. Cavalheiro, E. T. G.; Ionashiro, M.; Breviglieri, S. T.; Marino, G.; Chierice, G. O.; Quim. Nova 1995, 18, 305.

9. Bernal, C.; Couto, A. B.; Breviglieri, S. T.; Cavalheiro, E. T. G.; Quim. Nova 2002, 25, 849.
10. Ionashiro, M.; Giolito: Fundamentos da Termogravimetria e Análise Térmica Diferencial e Calorimetria Exploratória Diferencial, Giz Editorial: São Paulo, 2005.

11. Okumura, F.; Cavalheiro, E. T. G.; Nóbrega, J. A.; Quim. Nova 2004, 27, 832.

12. Skoog, D. A.; West, D. M.; Holler, F. J.; Princípios de Análise Instrumental, $5^{\text {a }}$ ed., Bookman: Porto Alegre, 2002.

13. Dean, J. A.; Flame Photometry, McGraw-Hill: New York, 1960.

14. Mendham, J.; Denney, R. C.; Barnes, J. D.; Thomas, M.; Vogel - Análise Química Quantitativa, 6a ed., LTC: Rio de Janeiro, 2002.

15. Clement, D.; Inorganic Thermogravimetric Analysis, Elsevier: New York, 1963.

16. Kalinkin, A. M.; Kalinkina, E. V.; Zalkind, O. A.; Makarova, T. I.; Inorg. Mater. 2005, 41, 1073.

17. Fukuda, Y.; Tanabe, K.; Bull. Chem. Soc. Jpn. 1973, 46, 1616.

18. Blom, C. E.; Hedderich, H. G.; Chem. Phys. Lett. 1988, 145, 143.

19. Harris, D. C.; Análise Química Quantitativa, 6 ${ }^{\mathrm{a}}$ ed., LTC: Rio de Janeiro, 2005 . 